\title{
Analysis of the effect of comprehensive nursing intervention on pulmonary infection in patients with severe neurosurgery.
}

\author{
Xiaohua Jiang, Jian Tang* \\ Sichuan Academy of Medical Sciences, Sichuan Provincial People's Hospital, PR China
}

\begin{abstract}
Objective: Investigated the effect of comprehensive nursing intervention on the prevention of pulmonary infection in severe patients in department of neurosurgery.

Methods: Randomly divided 89 patients with neurosurgical intensive cases admitted in our hospital from April 2014 to September 2016 into two groups, 43 patients in the control group underwent routine neurosurgical care, and 46 cases in the observation group underwent comprehensive nursing intervention. Compared the Barthel index score, tracheotomy time, the length of ICU stay and hospital stay between the two groups before and after nursing care, and observed the lung infection and satisfaction.

Results: There was no significant difference in daily living ability and Barthel index score between the two groups $(P>0.05)$, which were significantly improved after treatment. And the observation group was significantly higher than that of the control group, the difference between the two groups was statistically significant $(P<0.05)$, the incidence of lung infection, aspiration, expectoration and hypoxemia in the observation group were lower than those in the control group, and the differences were statistically significant $(\mathbf{P}<\mathbf{0 . 0 5})$. In addition, the overall satisfaction of the observation group was 95.65\%, which was higher than that of the control group (79.07\%), and the difference was significant (P<0.05).

Conclusion: Comprehensive nursing intervention on the prevention of pulmonary infection in severe patients in department of neurosurgery can not only promote the recovery of patients, but also can effectively prevent complications such as lung infection, improve living ability.
\end{abstract}

Keywords: Comprehensive nursing intervention, Pulmonary infection, Severe neurosurgery.

Accepted on December 18, 2017

\section{Introduction}

Severe patients in neurosurgery department are in critical conditions mostly accompanied with respiratory dysfunction after onset. Most of them need tracheal intubation or placement of tracheal tube in vitro after surgery to maintain respiration. Operations above belong to invasive operation, easily to cause pulmonary infection and other complications, further, heavy burden on body, thus, influencing treatment of primary diseases and prognostic effects [1]. The studies find that [2] pulmonary infection of severe patients in neurosurgery department mainly caused by disturbance of consciousness, in addition, invasive operation may cause function physiological reflection function declines, such as swallow, cough and so on, difficulty of vomitus and phlegm extraction and so on furtherly. Finally, producing pulmonary infection caused by error extraction. Furthermore, tracheal intubation injuries respiratory mucosa, increases risk of pulmonary infection furtherly [3]. Therefore, nursing for severe patients in neurosurgery department is critical. Studies before point out comprehensive nursing intervention can improve ability of daily life and promote recovery of patients [4]. There are also studies [5] showing that comprehensive nursing intervention plays an important role in lowering pulmonary infection.

\section{Materials and Methods}

\section{General data}

This study selected 89 severe patients in neurosurgery department from April, 2014 to September, 2016 in our hospital. Inclusive data: patients' families signed consent form. It was approved by hospital ethics committee. The cases data are complete. Exclusive criteria: Patients who not met criteria above; patients or their families with severe mental problems or intelligence growth disorder who cannot finish the investigation; patients who had poor compliance or unwilling to cooperate; Study personnel who were willing to quit halfway. They were divided into two groups randomly. 43 cases in the control group were given routine neurosurgical nursing. The ratio of male and female was $24 / 19$. The age was from 27 to $60 \mathrm{y}$ old. The average age was $38.12 \pm 6.02 \mathrm{y}$ old. The time from visit to disease onset was from 1 to $24 \mathrm{~h}$. The average time was $2.15 \pm 0.79 \mathrm{~h}$. GCS when they were admitted 
into hospital were from 3 to 7 . The average score was $5.65 \pm$ 0.49. There were 19 severe cranial-cerebral injury, 11 subarachnoid hemorrhage, 2 intracranial tumor rupture, 9 cerebral hemorrhage caused by hypertension, 2 cerebral hemorrhage. 46 cases in the observation group were given comprehensive nursing intervention, the ratio between male and female was $25 / 21$. The age was from 25 to $58 \mathrm{y}$ old. The average age was $37.65 \pm 7.45$. The time from visit to onset was from 1 to $35 \mathrm{~h}$. The average time was $37.65 \pm 7.45$. GCS when they were admitted into hospital were from 3 to 9 . The average score was $5.85 \pm 0.67$. There were 20 severe crania-cerebral injury, 12 subarachnoid hemorrhage, 2 intracranial tumor rupture, 10 cerebral hemorrhage caused by hypertension, 2 cerebral hemorrhage. There were no statistical differences in general data in two groups, such as sex, age and conditions and so on $(\mathrm{P}>0.05)$. It had comparability.

\section{Methods}

The control group: It was given routine nursing for severe patients in neurosurgery department, nursing at different levels according to doctor's advice, communication, diet guide, psychological intervention and rehabilitation guide according to demand of patients.

The observation group: it was given comprehensive nursing. First, psychological intervention: patients were given individualized psychological counselling after admitted into hospital, adequate consideration, making they feel receives much concern. And this method guided patients drain bad emotions through confiding, families to cooperate nursing after revival, thus, guaranteeing its stimulus on brain. In addition, nurse personnel should learn family conditions of patients, avoid psychological pressure caused by economic status, counsel positively to tell this was a transition to patient's families. Positive treatment will make the situation get better to strengthen the confidence of patients. Second, exercise rehabilitation nursing: during nursing, we should guarantee the limb function of patients, this method gave proper nursing to prevent edema or spasm of joint and muscle. It guided patients to turn over frequently to prevent phlebothrombosis formation caused by lying in bed for a long time. After stability of patients' conditions, then the method guided them finished rehabilitation from initiative state to passive state. The rehabilitation in bed mainly was moving body on time, turn over, trunk movement, exchange of seat state and recumbent position and so on. There was stance position, seat balance, shifting of weight, less up and down stairs movement and so on. Third, nursing intervention of cognitive dysfunction: this method should mater the changes of cognitive function of patients from time to time, in the early stage of rehabilitation, it can provide familiar music broadcast for patients, encourage patients' families to accompany and communicate with patients frequently. Through voice to stimulate perception of patients, enhance their cognitive ability for environment to accelerate awareness process of patients. During rehabilitation, most used thinking, memory ability and training of attention ability so as to promote concentration ability of patients, relieve paraphasia, orientation reduction degree, then to detect ability of seriation, classification and fill in gaps. of patients. In the later stage of clinical rehabilitation, strengthening adaptation ability and dealing with problems independently in different environments to enhance recovery of cognitive ability of patients. Fourth, daily life ability training: these methods evaluated daily life ability, formulated training plan aimed at study ability. Training including stance, seat position, metastasis, walking, wearing closes, individual sanitation, dinner and so on. The training should use step-by-step methods, strengthening difficulty and intensity of training action to help recover self-care ability of patients.

\section{Observation indexes}

Compared Barthel indexes scores, tracheotomy time, admitted into ICU and hospital time of daily life ability before and after nursing of patients in two groups and observed pulmonary infection and satisfaction in two groups.

Diagnostic criteria of pulmonary infection: It referred to relevant diagnostic criteria of hospital acquired bronchial pulmonary infection [6]. Patients had clinical symptoms, such as tachypnea, pus secretion of respiratory tract, WBC over 10 $\times 10^{9} / \mathrm{L}$, body temperature over $38^{\circ} \mathrm{C}$. Iconography (including $\mathrm{X}$-ray) chest radiography showed that pulmonary inflammatory lesions. Pulmonary auscultation can detect dry and wet rale. Examination and diagnosis were given clinical manifestations, bacteriology and hemogram comprehensively.

Daily life ability evaluation: It used Barthel indexes evaluation method to evaluate whether patients' daily life was independent, defecation control, self-intake ability, taking a bath, wearing closes and walking and so on [7]. Total score were from 0 to 100 . The higher then scores, the better the daily life ability of patients.

Nursing satisfaction evaluation: After nursing, independent consciousness patients who should evaluate by themselves [8]. For patients without clear consciousness should be evaluated by their families before discharge according to the subjective consciousness of evaluation people. The total score was 100 . The score equal to or over 80 represented satisfaction; 60 to 79 represented basic satisfaction; below 60 meant unsatisfactory state. Total satisfaction $=($ satisfactory number $) /$ total number $\times$ 100\%. Questionnaire was stored strictly after accomplishment to avoid human alternation.

\section{Statistical analysis}

This study used SPSS 18.0 to data management. Measurement data used $\overline{\mathrm{x}} \pm \mathrm{s}$ for description and used t-test. Numeration data used $\mathrm{n}(\%)$ for description. Ranked data used Wilcoxon ransum test. Calculating $Z$ value. Non-ranked data used $\chi^{2}$ test. $\mathrm{P}<0.05$, there were statistical differences.

\section{Results}

Daily life ability Barthel indexes scores comparison of patients in two groups before nursing and in the first month after discharged from hospital. 
Analysis of the effect of comprehensive nursing intervention on pulmonary infection in patients with severe neurosurgery

There were no statistical differences in daily life ability Barthel indexes scores before nursing $(\mathrm{P}>0.05)$; two groups after nursing improved obviously compared with before nursing, and daily life ability Barthel indexes scores higher than the control group in the first month after discharged from hospital, there were statistical differences $(\mathrm{P}<0.05$, Table 1$)$.

\section{Patients in two groups}

Tracheotomy, ICU admitted time and hospital time in the observation group lower than the control group, the medical cost in the observation group less than the control group obviously, there were statistical differences $(\mathrm{P}<0.05$, Table 2$)$.

\section{Comparison of complications of patients in two groups}

Pulmonary infection, error extraction, unsmooth phlegm discharge, hypoxemia incidence rate in the observation group lower than the control group, there were statistical differences $(\mathrm{P}<0.05$, Table 3).

\section{Comparison of nursing satisfaction of patients in two groups}

There were statistical differences in nursing satisfaction of patients in two groups $(\mathrm{P}<0.05)$, the observation group higher than the control group (Table 4).

Table 1. Daily life ability Barthel indexes scores comparison of patients in two groups before nursing and in the first month after discharged from hospital.

\begin{tabular}{llllll}
\hline Group & Cases & $\begin{array}{l}\text { Before } \\
\text { nursing }\end{array}$ & $\begin{array}{l}\text { The } \\
\text { month first t } \\
\text { discharged } \\
\text { from hospital }\end{array}$ & P \\
\hline $\begin{array}{l}\text { The observation } \\
\text { group }\end{array}$ & 46 & $50.02 \pm 8.12$ & $89.95 \pm 17.42$ & 14.091 & $<0.01$ \\
\hline $\begin{array}{l}\text { The } \\
\text { group }\end{array}$ & & $49.69 \pm 9.07$ & $74.02 \pm 16.39$ & 8.517 & $<0.01$ \\
\hline $\mathrm{t}$ & & 0.181 & 4.436 & & \\
\hline $\mathrm{P}$ & & 0.857 & $<0.01$ & & \\
\hline
\end{tabular}

Table 2. Comparison of general conditions of patients in two groups before and after surgery.

\begin{tabular}{|c|c|c|c|c|c|}
\hline Group & Cases & Tracheotomy time (min) & ICU admitted time (d) & Hospital time (d) & Medical cost (Yuan) \\
\hline The observation group & 46 & $7.21 \pm 1.35$ & $4.68 \pm 1.02$ & $22.02 \pm 2.68$ & $15053.25 \pm 1765.46$ \\
\hline The control group & 43 & $10.69 \pm 1.05$ & $6.69 \pm 1.15$ & $29.35 \pm 3.45$ & $16995.56 \pm 1685.02$ \\
\hline $\mathrm{t}$ & & 13.509 & 8.736 & 11.234 & 5.302 \\
\hline $\mathrm{P}$ & & $<0.01$ & $<0.01$ & $<0.01$ & $<0.01$ \\
\hline
\end{tabular}

Table 3. Comparison of complications of patients in two groups.

\begin{tabular}{llllll}
\hline Group & Cases & $\begin{array}{l}\text { Pulmonar } \\
\text { y infection }\end{array}$ & $\begin{array}{l}\text { Unsmooth } \\
\text { phlegm } \\
\text { discharge }\end{array}$ & $\begin{array}{l}\text { Error } \\
\text { extraction }\end{array}$ & Hypoxexia \\
\hline $\begin{array}{l}\text { The } \\
\text { observation } \\
\text { group }\end{array}$ & 46 & $2(4.34)$ & $2(4.34)$ & $0(0.00)$ & $2(4.34)$ \\
\hline $\begin{array}{l}\text { The control } \\
\text { group }\end{array}$ & 43 & $9(20.93)$ & $8(18.60)$ & $4(9.30)$ & $8(18.60)$ \\
\hline$X^{2}$ & & 5.642 & 4.529 & 4.480 & 4.529 \\
\hline$P$ & 0.018 & 0.033 & 0.034 & 0.033 \\
\hline
\end{tabular}

Table 4. Comparison of complications of patients in two groups.

\begin{tabular}{llllll}
\hline Group & Cases & $\begin{array}{l}\text { Satisfactor } \\
\mathbf{y}\end{array}$ & $\begin{array}{l}\text { Basic } \\
\text { satisfactory }\end{array}$ & $\begin{array}{l}\text { Unsatisfactor } \\
\mathbf{y}\end{array}$ & $\begin{array}{l}\text { Total } \\
\text { satisfactio } \\
\mathbf{n}\end{array}$ \\
\hline $\begin{array}{l}\text { The } \\
\text { observatio } \\
\mathrm{n} \text { group }\end{array}$ & 46 & $29(63.04)$ & $15(32.61)$ & $2(4.34)$ & 95.65 \\
\hline $\begin{array}{l}\text { The } \\
\text { control } \\
\text { group }\end{array}$ & 43 & $12(27.91)$ & $22(51.16)$ & $9(20.93)$ & 79.07 \\
\hline Z/ $x^{2}$ & & & & \\
\hline
\end{tabular}

$$
\mathrm{P}
$$

$<0.01$

0.018

\section{Discussion}

The neurosurgery department mainly receive surgical treatment patients, such as acute cerebral hemorrhage, intracranial tumor, severe inflammation and so on. The conditions of severe patients are complicated and changes frequently. Though some patients have slight cranial-cerebral injury, it is difficult to find, but with time going on, the conditions get worse, even threat patients' life [9]. Clinical to do the rescue through invasive operation, such as tracheal intubation. Therefore, pulmonary infection has become the common complications of severe patients in neurosurgery after surgery, and its incidence rate higher than other departments. The harm is relatively high. Comprehensive nursing is a kind of nursing mode with psychological, physiological and diseases. Studies before [10] demonstrate that the effects of comprehensive nursing intervention for neurosurgery patients are obvious.

Cognitive function means a kind of ability of recognizing relations between yourself and surrounding environments, belongs to high-level activity area of cerebral cortex, mainly including cognition, attention, memory, intelligence, language and understanding ability and so on $[11,12]$. In general, neurological injury can cause cognitive dysfunction at different 
levels, further causing abnormal changes of patients, such as illusion, orientation, attention and so on. But cognitive function plays an important role in actions of patients and emotion control. So we can see rehabilitation of cognitive function of severe patients in neurosurgery is vital for disease prognosis. In the results, comprehensive intervention group is given cognitive function rehabilitation. Daily life ability Barthel indexes improve significantly in the first month after discharged from hospital. So we can see, comprehensive nursing intervention can promote postoperative recovery of severe patients in neurosurgery department, improve life quality. The results are in accordance with studies of Guo et al. $[13,14]$. And hospital stay time and ICU time after surgery in comprehensive nursing group shorter than the routine nursing group. During comprehensive nursing intervention, because most severe patients in neurosurgery department has received injury severely, causing great stimulation on psychological aspect. They are venerable after trauma. The burden ability is relatively low, easily have conditions, such as anxiety, depression, sleep and diet disorder. Therefore, giving proper psychological nursing for severe patients in neurosurgery can relive theory bad emotions, furtherly strengthen confidence for disease treatment of patients and acquire patients' cooperation. In addition, the results show that satisfaction of patients in comprehensive nursing group higher than the routine nursing group significantly, it mainly in comprehensive nursing intervention not only pay attention to nursing for disease, also psychological state of patients. Developing communication since admitted into hospital will bring full concern and love to patients, furtherly promoting harmonious relations between nurses and patients. This study analyse pulmonary infection and other complications of severe patients in neurosugery. So we can see that pulmonary infection, error extraction, unsmooth phlegm extraction and hypoxemia incidence rate lower than routine nursing group obviously. Because during nursing conduction process, the comprehensive nursing intervention requires to follow sterile operation strictly, keep effective communication with patients before and after operation, learn the comfortable and proper position during surgery, thus, promoting cooperation of patients, avoiding operation risk during surgery. Furthermore, common tracheotomy used in severe patients in neurosurgery department mainly relies on internal and external environment of intubation connection. Therefore, any improper operation all can cause pulmonary infection of patients, so cooperation of patients is vital for surgery. In addition, it needs cooperation of nurses with adequate phlegm extraction experience. Zheng et al. $[15,16]$ also point out that comprehensive nursing can reduce pulmonary infection risk of patients after tracheotomy effectively.

In conclusion, comprehensive nursing intervention for severe patients in neurosurgery department not only can promote recovery of patients, also can prevent complications, such as pulmonary infection, improve life quality.

\section{References}

1. Lv XX. Effects analysis of comprehensive nursing on 39 severe patients in neurosurgery department. Contemp Clin J 2016; 29: 2514.

2. Zhao L, Zhuo CG. Application and study on TCM in severe diseases monitor in neurosurgery. Yi Yao Qianyan 2016; 6: 316-317.

3. Zhang QY, Zhong QR. Influence of comprehensive nursing intervention on gastroesophageal reflux of tracheotomy patients. Chinese J Pract Nurs 2011; 27: 35-36.

4. Tang XH, Xu YL, Yuan B. Nursing on 12 cases with phlebothrombosis of severe patients in neurosurgery department after surgery. Chinese J Misdiag 2011; 11: 6026-6026.

5. Hosseini M, Salehi A, Fallahi K M. The effect of a preoperative spiritual/religious intervention on anxiety in Shia Muslim patients undergoing coronary artery bypass graft surgery: a randomized controlled trial. J Holist Nurs Off J Am Holist Nurses Assoc 2013; 31: 164.

6. Jing XG. Explore the clinical effects of comprehensive nursing on preventing pulmoanry infection of severe patients in neurosugery department. China Health Industr 2014; 27: 93-94.

7. Liu W. Effects observation on comprehensive nursing intervention in severe patients in neurosurgery. China Sanit Crit Manag 2016; 7: 237-238.

8. Liu XJ. Application and evaluation of comfortable nursing on ICU in neurosurgery department. Chinese Pract Med 2013; 8: 217-218.

9. Guo YJ. Application and effects evaluation of music nursing on ICU in neurosurgery department. Chinese practical Nerv Dis 2012; 15: 89-90.

10. Ai F, Fen Q, Li JR. Clinical observation and nursing analysis on 210 severe cranial-cerebral blood edema. Jilin Med 2012; 33: 3998-3999.

11. Zhou LL. Clinical nursing study on tracheotomy of severe cranial-cerebral injury. J Clin Nurs Pract 2017; 2: 107-110.

12. Collet AV. Tracheotomy in patient with severe cranial injury. Revue Doto-Neuro-Ophtalmol 1958; 30: 490.

13. Guo JL, Zhang YF, Wang XY. Effects observation on comprehensive nursing on preventing pulmonary infection of severe patients in neurosurgery department. Int Med Health Guid News 2013; 19: 1022-1024.

14. Zhang YH. Clinical value of comprehensive nursing intervention in prevention of postpartum hemorrhage in uterine inertia. J Pract Gynecol Endocrinol 2016.

15. Zheng $\mathrm{YH}$, Gao $\mathrm{CH}$. Effects of comprehensive nursing intervention on preventing pulmonary infection of critical patients in neurosurgery department. West Med TCM 2014; 4: 132-133.

16. Shengnan XU, Wang L, Neurosurgery DO. Observation on the effect of comprehensive nursing intervention on patients with swallowing disorder of cerebral blood vessel. China Cont Med Educ 2016. 
Analysis of the effect of comprehensive nursing intervention on pulmonary infection in patients with severe neurosurgery

\section{*Correspondence to}

Jian Tang

Sichuan Academy of Medical Sciences

Sichuan Provincial People's Hospital

PR China 